\title{
Chapter 10 \\ High-Dose Three-Weekly or Low-Dose Weekly Cisplatin during Radiation, What to Prefer?
}

\author{
Petr Szturz and Jan B. Vermorken
}

\section{Introduction}

Since 1990s, chemoradiotherapy has been fulfilling an important role in the management of locally (and/or regionally) advanced squamous cell carcinoma of the head and neck (LA-SCCHN). In laryngeal and hypopharyngeal cancers, the first-generation trials on organ preservation demonstrated that induction chemotherapy followed by radiotherapy could spare total laryngectomy in more than half of patients without jeopardizing overall survival [1, 2]. About a decade later, the second-generation trials compared different administration schedules of chemoradiotherapy, and the Radiation Therapy Oncology Group (RTOG) 91-11 study showed the highest yields of larynx preservation when chemotherapy and radiotherapy had been delivered concurrently [3,4]. In the same period, the latter schedule emerged as a preferred alternative to radiotherapy alone in unresectable cases without distant metastases and after surgical removal of locoregionally advanced disease in the presence of close or positive margins or extracapsular spread [5-7]. Subsequently, the recommended standard-of-care regimen has consisted of normofractionated external beam radiotherapy (2 Gy once per day five times weekly) combined with three cycles of concurrent highdose three-weekly cisplatin at a dose of $100 \mathrm{mg} / \mathrm{m}^{2}$, both in the definitive and adjuvant settings.

\footnotetext{
P. Szturz

Department of Oncology, Lausanne University Hospital (CHUV), Lausanne, Switzerland

J. B. Vermorken $(\bowtie)$

Department of Medical Oncology, Antwerp University Hospital, Edegem, Belgium and Faculty of Medicine and Health Sciences, University of Antwerp, Antwerp, Belgium

e-mail: JanB.Vermorken@uza.be
} 
While the addition of concomitant systemic treatment to radiotherapy positively impacts on locoregional control and survival, albeit to a limited extent, at the same time it does increase acute and late adverse events. Approaches to deal with these shortcomings are focussing either on modifications in radiotherapy or chemotherapy or both. An important step forward has been the implementation of intensitymodulated radiotherapy (IMRT) techniques leading to a reduction of acute and in particular late treatment-related toxic effects [8, 9]. In parallel, many efforts have been undertaken to ameliorate chemotherapy, but they did not produce any further practice-changing results. Theoretically, adjustments in systemic treatment schedules and finetuning of exposition to anticancer agents can modulate acute toxicity, whereas the objective of new systemic drugs or drug combinations has been primarily to improve efficacy. In this respect, the success story of immune checkpoint inhibitors in the recurrent and/or metastatic setting sparked hopes for patients with LA-SCCHN who are currently being offered participation in several large-scale randomized trials, which are ongoing in many centres globally, as further addressed below.

In this work, we will focus on weekly low-dose cisplatin, as an alternative to the standard, high-dose regimen, given concurrently to definitive or adjuvant radiotherapy in LA-SCCHN in order to decipher whether this change in administration schedule can influence acute toxicity as hypothesized above and what effect it may have on survival parameters. We will explore the comparison between weekly and three-weekly cisplatin at different levels of evidence according to the European Society for Medical Oncology (ESMO) grading consensus system and conclude with practice-oriented recommendations (Fig. 10.1) [10].

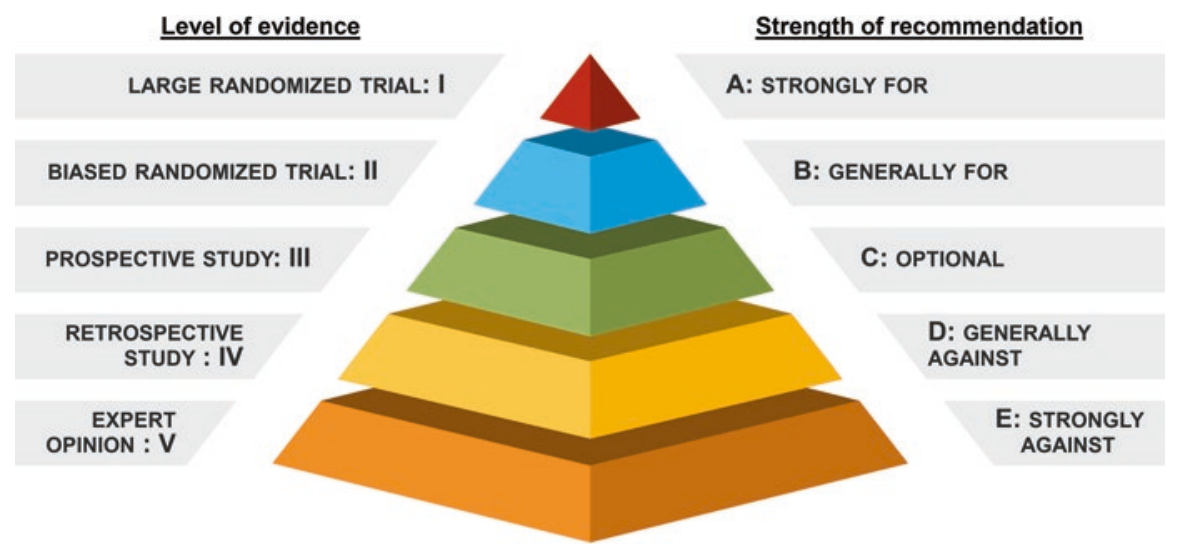

Fig. 10.1 Grading consensus system of clinical practice recommendations according to the European Society for Medical Oncology (ESMO) [10]. (C) Copyright PresentationGO.com (Pyramide) 


\section{High-Dose Three-Weekly Cisplatin}

Its position as the current standard of care has been built on the results of four large phase III trials published between 2003 and 2004 [3, 5-7]. Additional supporting data were provided in one smaller randomized study from 2004 [11]. The total intention-to-treat population of all these five trials together, three of which were conducted in the definitive and two in the adjuvant settings, equalled 1763 patients. Comparing concurrent chemoradiotherapy with radiotherapy alone, significantly enhanced disease-free survival (or its analogous measure), locoregional control, and overall survival were observed in favour of high-dose three-weekly cisplatin, which on the other hand had neither a significant influence on the incidence of distant metastases nor on response rate. More recently, enrolling exclusively treatmentnaive human papillomavirus (HPV)-positive oropharyngeal cancer cases, the role of this regimen has further been reinforced by two large phase III trials, RTOG 1016 and De-ESCALaTE, in which the comparator arm comprised bioradiation with single-agent cetuximab [12, 13]. Here again, high-dose three-weekly cisplatin unequivocally outperformed the latter arm in terms of locoregional control rate and survival. In addition, the De-ESCALaTE trial, including only low-risk oropharyngeal cancer cases (HPV-positive, smoking history of less than ten pack-years), found a significant decrease in distant metastasis after cisplatin treatment (3\% versus $9 \%, \mathrm{p}=0.0092$ ). Taken all seven trials together, the total intention-to-treat population reached up to almost 3000 patients (Table 10.1). Of note, contrastingly to the remaining studies, the RTOG 1016 study employed an accelerated radiotherapy technique with six fractions over five days weekly aiming at the standard total dose of $70 \mathrm{~Gy}$. As a general rule, altered fractionation radiotherapy has been combined with only two cycles of concurrent high-dose cisplatin given its shorter overall duration.

The efficacy, toxicity, and compliance of three-weekly high-dose cisplatin were explored in three meta-analyses of aggregate data, separately evaluating chemoradiotherapy based on conventional and on altered fractionations in the definitive and post-operative settings $[14,15]$. Among 31 prospective trials using conventionally fractionated radiotherapy, model-based estimates of 5-year overall survival were $39 \%$ and $51 \%$ in the definitive and adjuvant settings, respectively. Relative to radiotherapy alone, patients treated with the combined regimen experienced more grade III-IV acute toxicity. About $40 \%$ developed mucositis, up to one fourth difficulties with swallowing, and at least $20 \%$ bone marrow suppression. As a result, only about two thirds of them could receive all three planned cycles of high-dose cisplatin [14]. Due to a limited number of eligible trials with altered fractionation, the respective meta-analysis could be performed only in the definitive setting. The estimated 5-year overall survival increased to $57 \%$ and compliance with both cisplatin cycles was as high as $92 \%$. Nevertheless, severe acute adverse events remained frequent: $40 \%$ mucositis and dysphagia and about one out of five patients suffered from hematotoxicity [15]. 
Table 10.1 Overview of phase III trials exploring conventional radiotherapy with 3 cycles of $100 \mathrm{mg} / \mathrm{m}^{2}$ cisplatin ${ }^{\mathrm{a}}$ versus radiotherapy alone or bioradiation with cetuximab. Arrows pointing up symbolize significant improvements achieved by the addition of cisplatin, while the equals signs indicate a lack of statistically significant difference

\begin{tabular}{|c|c|c|c|c|c|c|c|}
\hline \multirow[b]{2}{*}{ Author, year } & \multirow[b]{2}{*}{ Setting } & \multirow[b]{2}{*}{ ITT } & \multicolumn{5}{|c|}{ Benefit of CRT vs. RT alone } \\
\hline & & & RR & DFS & LCR & DM & OS \\
\hline Adelstein, 2003 [5] & Definitive & 295 & $=$ & $\uparrow$ & $\mathrm{nr}$ & $=$ & $\uparrow$ \\
\hline Forastiere, $2003[3,17]$ & Definitive & 547 & $=$ & $\uparrow$ & $\uparrow$ & $\uparrow /=$ & $=$ \\
\hline Fountzilas, 2004 [11] & Definitive & 128 & $=$ & $\uparrow$ & $\mathrm{nr}$ & $\mathrm{nr}$ & $\uparrow$ \\
\hline Cooper, 2004 [6] & Adjuvant & 459 & $\mathrm{nr}$ & $\uparrow$ & $\uparrow$ & $=$ & $=$ \\
\hline \multirow[t]{3}{*}{ Bernier, 2004 [7] } & Adjuvant & 334 & $\mathrm{nr}$ & $\uparrow$ & $\uparrow$ & $=$ & $\uparrow$ \\
\hline & & 1763 & & & & & \\
\hline & & & \multicolumn{5}{|c|}{ Benefit of CRT vs. BRT alone } \\
\hline Mehanna, 2019 [13] & Definitive & 334 & $\mathrm{nr}$ & $\uparrow$ & $\uparrow$ & $\uparrow$ & $\uparrow$ \\
\hline \multirow[t]{2}{*}{ Gillison, 2019 [12] } & Definitive & 849 & $\mathrm{nr}$ & $\uparrow$ & $\uparrow$ & $=$ & $\uparrow$ \\
\hline & & 2946 & & & & & \\
\hline
\end{tabular}

$I T T$ intention-to-treat population of the entire study (all definitive trials had tree arms); $(C) R T$ (chemo)radiotherapy; $v s$. versus; $R R$ response rate; $B R T$ bioradiation with cetuximab; $n r$ not reported; DFS disease-free survival (progression-free survival in Bernier et al. and Gillison et al., disease-specific survival in Adelstein et al., time to progression in Fountzilas et al., recurrence rate in Mehanna et al.); DM distant metastases (benefit not confirmed in Forastiere 2013); OS overall survival

aaltered fractionation radiotherapy with 2 cycles of $100 \mathrm{mg} / \mathrm{m}^{2}$ cisplatin in Gillison et al.

Data on late toxicity should be regarded with caution because their reporting is scarce and usually biased due to difficulties with long-term follow-up of study participants. Although published results did not confirm that adding cisplatin leads to a significant increment in late side effects when compared with radiotherapy alone, it is plausible to assume the opposite. Not only has late toxicity been associated with long-term exposure to circulating platinum, but also the worse survival of patients randomized to the concurrent chemoradiation arm in the RTOG 91-11 trial suggests an important contribution of systemic treatment to late treatmentrelated morbidity $[16,17]$. In this respect, it is of interest to consider the role of radiotherapy technique, especially IMRT as alluded to above. In fact, the majority of studies employed conventional two-dimensional or three-dimensional conformal planning, which has been gradually replaced by IMRT since its introduction in clinical protocols about 15 years ago. In the aforementioned meta-analyses, only six out of 38 chemoradiotherapy trials with high-dose cisplatin used IMRT but never as an exclusive method $[14,15]$.

Finally, it is informative to balance the results obtained from the meta-analyses of studies on high-dose cisplatin in the definitive setting that opened for accrual between 1981 and 2011 and those obtained from the two most recent phase III trials, De-ESCALaTE and RTOG 1016, which recruited patients from 2011 to 2016 (Table 10.2). Compliance to normofractionated radiotherapy was better in the De-ESCALaTE study than observed in the meta-analysis, which partly could be attributed to the use of IMRT. Surprisingly, a much lower percentage of patients in 
Table 10.2 Compliance and toxicity based on per protocol calculations and expressed in percentages in patients with locally and/or regionally advanced squamous cell carcinoma of the head and neck treated with three-weekly high-dose cisplatin given concurrently to definitive radiotherapy [12-15]

\begin{tabular}{|c|c|c|c|c|}
\hline & \multicolumn{2}{|c|}{ Normofractionated } & \multicolumn{2}{|c|}{ Altered fractionation } \\
\hline & $\begin{array}{c}\text { Meta- } \\
\text { analysis }\end{array}$ & De-ESCALaTE & $\begin{array}{c}\text { Meta- } \\
\text { analysis }\end{array}$ & $\begin{array}{c}\text { RTOG } \\
1016\end{array}$ \\
\hline \multicolumn{5}{|l|}{ Compliance } \\
\hline RT: Completed without interruption & 84 & 93 & 76 & $\mathrm{nr}$ \\
\hline RT: Completed as prescribed & 90 & $100^{\mathrm{a}}$ & 95 & $95^{\mathrm{b}}$ \\
\hline CT: Received all planned cycles & 71 & 38 & 92 & 93 \\
\hline CT: Received at least $200 \mathrm{mg} / \mathrm{m}^{2}$ & 96 & 84 & 83 & $\mathrm{nr}$ \\
\hline CT: Received at least 2 cycles & 92 & 90 & 92 & 93 \\
\hline \multicolumn{5}{|l|}{ Severe acute toxicity (gr 3-4) } \\
\hline Anemia & 8 & 2 (SAE) & 5 & 3 \\
\hline Thrombocytopenia & 4 & $1(\mathrm{SAE})$ & 3 & 1 \\
\hline Leukopenia & 19 & $\mathrm{nr}$ & 18 & 12 \\
\hline Neutropenia & 18 & $2(\mathrm{SAE})$ & 18 & 15 \\
\hline Febrile neutropenia & 5 & 4 (SAE) & 5 & 5 \\
\hline Mucositis and/or stomatitis & 42 & 15 (SAE) & 40 & 42 \\
\hline Xerostomia & 2 & 0 (SAE) & 4 & 8 \\
\hline Dysphagia & 26 & 8 (SAE) & 40 & 37 \\
\hline Nausea and/or vomiting & 16 & 28/30 (SAE) & 17 & $19 / 12$ \\
\hline Weight loss & 12 & 4 (SAE) & 4 & 8 \\
\hline Anorexia & 6 & 10 (SAE) & 8 & 22 \\
\hline Laryngeal toxicity & 8 & $1(\mathrm{SAE})$ & 3 & $<1$ \\
\hline Nephrotoxicity & 5 & $7^{\mathrm{c}}$ & 5 & 3 \\
\hline Neurotoxicity & 2 & 6 & 3 & $<1$ \\
\hline Ototoxicity & 3 & 2 & 2 & 3 \\
\hline Skin toxicity & 11 & 4 & 13 & 8 \\
\hline Diarrhea & 2 & 4 (SAE) & 1 & 1 \\
\hline Constipation & 2 & 10 (SAE) & 1 & 1 \\
\hline Infection & 5 & 12 & 6 & 2 \\
\hline \multicolumn{5}{|l|}{$\begin{array}{l}\text { Mortality during CRT or within } \\
\mathbf{3 0} \text { days after completion }\end{array}$} \\
\hline Grade 5 toxicity & 3 & $\mathrm{nr}$ & 1 & 1 \\
\hline 30-day mortality & 4 & $\mathrm{nr}$ & 3 & 2 \\
\hline \multicolumn{5}{|l|}{ Late toxicity } \\
\hline Overall prevalence (gr 3-4) & 20 & $30^{\mathrm{d}}$ & 43 & 20 \\
\hline Xerostomia (gr 1-2) & 59 & $\mathrm{nr}$ & 72 & 85 \\
\hline Xerostomia (gr 3-4) & 10 & $\mathrm{nr}$ & 6 & 2 \\
\hline Dysphagia (gr 3-4) & 10 & $\mathrm{nr}$ & 12 & 4 \\
\hline Subcutaneous fibrosis (gr 3-4) & 5 & 0 & 2 & 0 \\
\hline
\end{tabular}

$R T$ radiotherapy; $C T$ chemotherapy; $g r$ grade; $S A E$ serious adverse events; $n r$ not reported

${ }^{a}$ Defined as having received at least 65 Gy

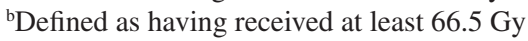

${ }^{\mathrm{c}}$ Renal and urinary disorders

${ }^{\mathrm{d} I n c l u d i n g}$ grade 5 toxicity 
De-ESCALate received all planned cisplatin cycles, which is more difficult to explain. Patient factors (demographics), treatment factors (hydration schema, antiemetic regimen), and physician factors (motivation based on literature data [18]) all might have played a role in this. Despite the lower exposition to cisplatin, overall survival was excellent with a 2-year estimate of 97.5\%. Otherwise, interpretation of toxicity in De-ESCALaTE is hampered by incomplete data reporting and substitution of grade III-IV acute toxicity for serious adverse events [13, 14]. Concerning altered fractionation, probably owing to a smaller target dose of cisplatin, compliance and severe acute side effects were comparable between RTOG 1016 and the older trials included in the meta-analysis on altered fractionation schedules using the high-dose cisplatin regimen. The lower overall prevalence of severe late toxicity in RTOG 1016 than in the meta-analysis may pertain to the use of IMRT in this study. This could have also contributed, along with superior prognosis of HPVpositive oropharyngeal cancer patients, to the unprecedented 5-year overall survival of $85 \%$ relative to the other phase III trials $[12,15]$.

\section{Low-Dose Weekly Cisplatin}

Low-dose weekly cisplatin regimens have gained attention primarily in an attempt to improve treatment tolerance by decreasing acute side effects. Here, we will show that the supporting evidence for these schedules is considerably weaker than what we have for the high-dose cisplatin regimen, mainly with respect to efficacy and late toxicity. This does not necessarily mean that a low-dose regimen is inferior, but more data are needed to substantiate the arguments. First, the mere definition remains elusive. It is generally accepted that weekly cisplatin should be given once per week during the course of radiotherapy but due to local variations in radiotherapy protocols, the number of administrations varies between six and seven and may be further perturbated by unpredictable factors sometimes producing space for an additional eighth cycle. Ranging usually between 20 and $50 \mathrm{mg} / \mathrm{m}^{2}$, an even greater dilemma arises when choosing the individual cisplatin dose [19]. Consequently, the concept of cumulative dose has been introduced as a possible solution to this conundrum. Retrospective evidence suggests that the overall survival benefit observed in several clinical trials was driven by patients who received a cumulative dose of at least $200 \mathrm{mg} / \mathrm{m}^{2}$ and this particularly if they had HPV-positive cancer of the oropharynx [13, 18, 20, 21]. Although this hypothesis has never been confirmed prospectively, its adaptation in clinical practice can be useful in situations when the risk of serious toxic complications escalates near the end of treatment [22]. In fact, it remains unknown whether pushing the total dose beyond $200 \mathrm{mg} / \mathrm{m}^{2}$ adds an additional advantage in overall survival or whether this benefit, reported recently in the literature, merely reflects a process of selecting patients with better health status who in general have a better prognosis and are able to tolerate quantitatively more chemotherapy [23]. In this respect it is intriguing to note that in De-ESCALaTE, patients who received all three cycles of $100 \mathrm{mg} / \mathrm{m}^{2}$ cisplatin did not experience 
more toxicity events than the total population, and grade III-V late adverse events even seemed to be less common [13].

Analogously to high-dose cisplatin, the low-dose regimen underwent prospective evaluation versus radiotherapy alone in four trials randomly assigning a total of 834 patients [24-28]. When looking at Table 10.3 summarizing these studies, the first thing to notice is a seemingly positive correlation between the cumulative dose of cisplatin and the efficacy of weekly regimens. Exploring seven weekly doses of $20 \mathrm{mg} / \mathrm{m}^{2}$, the largest and oldest study was published 24 years after the last patient had been accrued. The delay was probably due to the disappointing results which nonetheless contribute to our better understanding of cisplatin pharmacodynamics. In the chemoradiotherapy arm, overall survival was numerically lower and both acute and late toxicity significantly higher than in the comparator arm [24]. A benefit in overall survival was seen only in the two studies in which the majority of patients received a cumulative dose of at least $200 \mathrm{mg} / \mathrm{m}^{2}$ cisplatin. They were reported by Sharma et al., who had chosen seven weekly doses of $40 \mathrm{mg} / \mathrm{m}^{2}$, and Bachaud et al. with seven to nine doses of $50 \mathrm{mg} / \mathrm{m}^{2}$ [26-28]. Of note, the last study, by Ghosh-Laskar et al. (seven to eight doses of $30 \mathrm{mg} / \mathrm{m}^{2}$ ), had to be prematurely closed because of poor accrual. Despite the initial plan to administer at least $210 \mathrm{mg} /$ $\mathrm{m}^{2}$, the median cumulative dose of cisplatin was only $180 \mathrm{mg} / \mathrm{m}^{2}$, and this fell short of translating the significant yields in disease-free survival and locoregional control into a meaningful gain in overall survival [25]. Taken the four studies together, the addition of weekly cisplatin increased the frequency and severity of acute adverse events with less pronounced impact on late toxicity, the latter of which reached statistical significance only in the first study reported by Quon et al. and was not reported in the study by Sharma et al. [24, 26].

Table 10.3 Overview of randomized trials exploring conventional radiotherapy with weekly lowdose cisplatin versus radiotherapy alone

\begin{tabular}{l|c|c|c|c|c|c|c|c|c|c}
\hline & & & \multicolumn{4}{c|}{} & \multicolumn{2}{c}{$\begin{array}{c}\text { Total cisplatin } \\
{\left[\mathrm{mg} / \mathrm{m}^{2}\right]}\end{array}$} \\
\hline & & & \multicolumn{3}{c}{ Benefit of CRT vs. RT alone } & \multicolumn{2}{c}{} \\
\cline { 4 - 11 } Author, year & Setting & ITT & RR & DFS & LCR & DM & OS & Planned & Received \\
\hline Quon, 2011 [24] & Definitive & 371 & $=$ & $=$ & $\mathrm{nr}$ & $\mathrm{nr}$ & $=$ & 140 & $\mathrm{nr}$ \\
\hline Ghosh-Laskar, 2016 [25] & Definitive & 199 & $\mathrm{nr}$ & $\uparrow$ & $\uparrow$ & $=$ & $=$ & $210-240$ & $180^{\mathrm{a}}$ \\
\hline Sharma, 2010 [26] & Definitive & 176 & $\uparrow$ & $=$ & $=$ & $=$ & $\uparrow$ & 280 & $92 \%^{\mathrm{b}}$ \\
\hline Bachaud, 1991 [27] & Adjuvant & 88 & $\mathrm{nr}$ & $\uparrow$ & $\uparrow$ & $=$ & $\uparrow$ & $350-450$ & $59 \%^{\mathrm{c}}$ \\
\hline & & $\mathbf{8 3 4}$ & & & & & & & \\
\hline
\end{tabular}

Arrows pointing up symbolize significant improvements achieved by the addition of cisplatin, while the equals signs indicate a lack of statistically significant difference

ITT intention-to-treat population of the entire study (tree arms in Ghosh-Laskar et al.); (C)RT (chemo)radiotherapy; $R R$ response rate; $n r$ not reported; $D F S$ disease-free survival (failure-free survival in Quon et al., progression-free survival in Sharma et al.); $D M$ distant metastases; $O S$, overall survival ${ }^{a}$ Given median cumulative dose ${ }^{\mathrm{b}} \mathrm{Of}$ patients received planned cumulative dose

'Of patients received all planned cycles (at least 7, corresponding to a cumulative dose of $\left.350 \mathrm{mg} / \mathrm{m}^{2}\right)$ 
To further report on the outcomes of Iow-dose cisplatin, we will refer to the previously mentioned meta-analyses. They were conceptualized to compare the standard, high-dose three-weekly cisplatin with a weekly regimen complying with the vaguely defined dose and frequency criteria. Altogether, 38 trials were included in the high-dose arms and 21 in the low-dose arms of the three meta-analyses performed separately in the definitive conventionally fractionated, adjuvant conventionally fractionated, and definitive altered fractionation chemoradiotherapy settings. By involving uncontrolled studies and selected arms of otherwise ineligible randomized trials, one of their major limitations was that the final populations they compared were not intended to be compared and differed thus qualitatively but also quantitatively. Nevertheless, they fill the gap because there are hardly any unbiased randomized trials comparing these two schedules [19]. The results pertaining to weekly cisplatin will be presented in the following paragraph in relation to what has already been stated about the three-weekly schedule.

\section{High-Dose Three-Weekly Versus Low-Dose Weekly}

Aiming at a comprehensive approach to the topic, we will provide a step-wise evaluation and a concise overview of available evidence divided into 5 levels according to the model adopted by ESMO (Fig. 10.1) [10].

\section{Level V Evidence}

The lowest level of evidence is based on expert opinions, cross-sectional studies, case reports, and case series. Consequently, the assumptions underpinning low-dose weekly cisplatin in comparison with the high-dose regimen include a better shortand long-term tolerance without jeopardizing outcome, improved compliance, timely dose adjustments, enhanced radiosensitization, reduced risk of radioresistance, and lower costs due to outpatient administration [14]. Of them, those exploring efficacy, toxicity, and compliance were explored at higher levels of evidence and will be further discussed below. Radiobiological properties per se and logistical aspects have clinical relevance primarily if they influence patient outcomes, and they have not been studied separately in prospective cohorts. Costeffectiveness issue have recently been gaining increasing attention, but data are mostly available for new medicines. Based on a small retrospective study of 62 patients, the incremental cost-effectiveness ratio (ICER) for the addition of threeweekly cisplatin to radiotherapy was calculated at $\$ 3303$-per-quality-adjusted life year (QALY) [29]. An analysis of healthcare expenditures in the cisplatin arm of the De-ESCALaTE trial revealed total costs of $£ 13,517$ per patient at 24 months posttreatment [30]. Unfortunately, similar analyses are neither available for a weekly 
regimen versus radiotherapy alone nor for a comparison between the two cisplatin schedules under question.

\section{Level IV Evidence}

Retrospective cohort and case-control studies provide a higher level of evidence but are still difficult to pool. As summarized in one of our publications, the results of such studies comparing weekly versus three-weekly cisplatin are conflicting and do not allow us to make firm conclusions, albeit that an overall impression of their outcomes tends to endorse the high-dose regimen [14].

\section{Level III Evidence}

Moving on to non-randomized prospective trials we present here the key results of the set of three meta-analyses mentioned above [14, 15]. In the adjuvant setting of conventionally fractionated chemoradiotherapy, data from nine trials could be retrieved, six on high-dose and three on low-dose cisplatin. While no differences in late toxicity $(\mathrm{p}=0.5938)$ and compliance $(\mathrm{p}=0.5747)$ were observed, severe acute toxicity favoured the weekly schedule with significantly less dysphagia $(p=0.0026)$ and weight loss $(\mathrm{p}<0.0001)$. However, the latter findings should be interpreted with caution as they are based on only one trial using weekly cisplatin. In the definitive setting of conventionally fractionated chemoradiotherapy, 39 studies were included in the analysis, 25 in the high-dose and 14 in the low-dose cohort. There were clearly less severe acute toxicities with the weekly regimen as reflected by significantly less myelotoxicity (leukopenia: $\mathrm{p}=0.0083$; neutropenia: $\mathrm{p}=0.0024$ ), nausea and/or vomiting $(\mathrm{p}<0.0001)$, and severe nephrotoxicity $(\mathrm{p}=0.0099)$. In line with that, also the compliance was better with the weekly cisplatin regimen. No data on late toxicity were available in the low-dose cohort, precluding thus further calculations. The efficacy outcomes provided interesting insights into the role of the cumulative cisplatin dose. Although no difference in overall survival was noted in either of these meta-analyses, only about two thirds of patients in the high-dose arm could receive all three cisplatin cycles, i.e. a cumulative dose of $300 \mathrm{mg} / \mathrm{m}^{2}$. But what if the target dose was not 300 but $200 \mathrm{mg} / \mathrm{m}^{2}$. In that case, would it still be possible to ensure sufficient efficacy but with notably lower acute toxicity?

As alluded to above, $200 \mathrm{mg} / \mathrm{m}^{2}$ might indeed provide an adequate exposition to the drug. Moreover, this is exactly the target cumulative dose used in the third metaanalysis run in the definitive setting of altered fractionation chemoradiotherapy that involved 11 studies, seven with high-dose and four with low-dose cisplatin. Here, two cycles of the former regimen generated significantly less severe acute toxicity (mucositis and/or stomatitis: $\mathrm{p}=0.0202$, constipation: $\mathrm{p}=0.0066$ ) and short-term mortality (toxic deaths: $\mathrm{p}=0.0168,30$-day mortality: $\mathrm{p}=0.0154$ ), but also less 
severe late adverse events (subcutaneous fibrosis: $p<0.0001$ ) than observed with the low-dose cisplatin regimen. In line with an improved compliance $(\mathrm{p}=0.0353)$, the vast majority of patients $(95 \%)$ receiving the high-dose regimen could receive both planned cycles. Finally, patients on high-dose cisplatin during altered fractionation radiotherapy lived longer than those receiving the weekly regimen during altered fractionation radiotherapy $(\mathrm{p}=0.0353)$. Albeit purely hypothetical, these results contribute to the ever-growing body of knowledge that supports a minimal cumulative dose of $200 \mathrm{mg} / \mathrm{m}^{2}$.

\section{Level of Evidence II}

Only two prospective trials randomly assigning LA-SCCHN patients to receive either the three-weekly high-dose or a weekly low-dose regimen have been published so far (Table 10.4) [31, 32]. Owing to an increased risk of bias arising from insufficient power and cumulative dose issues, we have assigned them to level of evidence II. The first study randomized 55 patients who were treated with the same mean radiotherapy and cisplatin doses $\left(208.5 \mathrm{mg} / \mathrm{m}^{2}\right.$ three-weekly versus $200.4 \mathrm{mg}$ / $\mathrm{m}^{2}$ weekly) but a cumulative dose of at least $200 \mathrm{mg} / \mathrm{m}^{2}$ could be delivered to significantly more patients in the high-dose arm (88.5\% versus $62.5 \%, \mathrm{p}=0.047)$. In spite of that, the low dose regimen proved to be more toxic $(\mathrm{p}=0.02)$, particularly with regard to severe mucositis $(38.5 \%$ versus $75.0 \%, \mathrm{p}=0.012)$. No differences in overall survival were noted at median follow-up of 12 months [31]. The accrual in the second randomized study reached up to 300 patients but concerns were raised about the different cumulative doses with $180-210 \mathrm{mg} / \mathrm{m}^{2}$ being the target exposure in the weekly cisplatin arm and $300 \mathrm{mg} / \mathrm{m}^{2}$ in the three-weekly arm. In the end, it was not that surprising to see the three-weekly regimen generating better locoregional control at 2 years $(58.5 \%$ versus $73.1 \%, \mathrm{p}=0.014)$ but at the cost of an

Table 10.4 Phase III trials comparing radiotherapy given concurrently either to three-weekly high-dose or to weekly low-dose cisplatin

\begin{tabular}{|c|c|c|c|c|c|c|c|}
\hline \multirow[b]{2}{*}{$\begin{array}{l}\text { Author, } \\
\text { Year }\end{array}$} & \multirow[b]{2}{*}{$\begin{array}{c}\text { Therapy } \\
\text { intent }\end{array}$} & \multirow[b]{2}{*}{$\begin{array}{l}\text { Study } \\
\text { arms }\end{array}$} & \multirow[b]{2}{*}{$\begin{array}{l}\text { Inclusion } \\
\text { period }\end{array}$} & \multicolumn{2}{|c|}{$\begin{array}{l}\text { Intention-to-treat } \\
\text { population }\end{array}$} & \multicolumn{2}{|c|}{$\begin{array}{c}\text { Concurrent cisplatin } \\
{\left[\mathrm{mg} / \mathrm{m}^{2}\right]}\end{array}$} \\
\hline & & & & $\begin{array}{c}\text {...of } \\
\text { both } \\
\text { study } \\
\text { arms }\end{array}$ & $\begin{array}{c}\text {...of the } \\
\text { cisplatin } \\
\text { arm }\end{array}$ & $\begin{array}{l}\text { planned } \\
\text { schedule }\end{array}$ & $\begin{array}{c}\text { planned } \\
\text { cumulative } \\
\text { dose }\end{array}$ \\
\hline \multirow[t]{2}{*}{$\begin{array}{l}\text { Tsan, } 2012 \\
{[31]}\end{array}$} & \multirow[t]{2}{*}{ Adjuvant } & Weekly & $\begin{array}{l}2008- \\
2010\end{array}$ & 55 & $\mathrm{nr}$ & $7 \times 40$ & 280 \\
\hline & & $\begin{array}{l}\text { Three- } \\
\text { weekly }\end{array}$ & & & $\mathrm{nr}$ & $3 \times 100$ & 300 \\
\hline \multirow[t]{2}{*}{$\begin{array}{l}\text { Noronha, } \\
2018 \text { [32] }\end{array}$} & \multirow{2}{*}{$\begin{array}{l}\text { Adjuvant } \\
(93 \%) \text { and } \\
\text { definitive }\end{array}$} & Weekly & $\begin{array}{l}2013- \\
2017\end{array}$ & 300 & 150 & $6-7 \times 30$ & $180-210$ \\
\hline & & $\begin{array}{l}\text { Three- } \\
\text { weekly }\end{array}$ & & & 150 & $3 \times 100$ & 300 \\
\hline
\end{tabular}

$n r$ not reported 
increment in severe acute toxicity $(71.6 \%$ versus $84.6 \%, p=0.006)$, namely vomiting, infection, hearing loss, hyponatremia, and myelotoxicity. Compliance and late toxicity were comparable [32].

\section{Level of Evidence I}

Current evidence has not attained this level, and the presented meta-analyses do not qualify because they were not primarily based on randomized trials exploring the respective comparison. The situation may be changing soon when the results of the phase II/III non-inferiority trial of the Japan Clinical Oncology Group (JCOG1008) are shared. Aiming to enrol 260 participants in the post-operative setting, the study has been ongoing since October 2016 with the primary objective of overall survival. The target cumulative doses were set to $300 \mathrm{mg} / \mathrm{m}^{2}$ and $280 \mathrm{mg} / \mathrm{m}^{2}$ for three-weekly and weekly cisplatin, respectively [33].

\section{Immunotherapy Trials}

After having defined new standards of care in the recurrent and/or metastatic setting, immune checkpoint inhibitors entered clinical trial design in LA-SCCHN challenging cisplatin-based chemoradiotherapy. In this respect, the majority of randomized trials are exploring immunotherapy on top of cisplatin by either intensifying definitive or adjuvant treatment (dubbed for our purposes design concept "A") or by giving it right after the standard definitive or adjuvant chemoradiotherapy (design concept "B"). Alternatively, immunotherapy can replace cisplatin creating thus pure immunoradiotherapy regimens. In the former type of trials, high-dose three-weekly cisplatin represents the preferred administration mode.

The design model " $\mathrm{A}$ " has been adopted for example by the following larger ( $>$ 100 participants) trials: JAVELINE Head \& Neck (NCT02952586), KEYNOTE-412 (NCT03040999), KEYCHAIN (NCT03383094), ADRISK (NCT03480672), and NIVOPOSTOP (NCT03576417). Here, sometimes preceded by a short lead-in phase with one dose of immunotherapy in eligible patients, chemoradiotherapy, as already mentioned, is typically based on the high-dose three-weekly cisplatin schedule (weekly regimen allowed in ADRISK) and combined with a programmed death-1 (PD-1) inhibitor (pembrolizumab or nivolumab) or an anti-PD-1 ligand (PD-L1) agent (avelumab or atezolizumab) in the experimental arm. Afterwards, patients are started on a maintenance phase with or without the immune checkpoint inhibitor for six to 12 months. The design model "B" stands for a classic two-arm concept where patients are assigned either to 1 year of immunotherapy or the same period of placebo or observation after having completed curative treatment as seen in IMvoke010 (NCT03452137) and EA3161 (NCT03811015). Other notable mentions comprise IMSTAR-HN (NCT03700905) and KEYNOTE-689 (NCT03765918) 
which are combining both design models. Finally, cisplatin-based chemoradiotherapy has been challenged by non-chemotherapy approaches in the NRG-HN005 (NCT03952585) and REACH (NCT02999087) trials.

\section{Concluding Remarks and Outlooks for the Future}

There are many drawbacks of high-dose cisplatin which is not by far the ideal solution to administer concurrently to curative radiotherapy. Particularly, toxicity has become an issue for many patients, sometimes with life-long consequences. And this is where a weekly regimen steps in with probably the greatest benefit in better short-term tolerance, such as less nausea, vomiting, transaminase elevations, ototoxicity, serum creatinine increase, and myelotoxicity. However, this might be offset by worse survival outcomes and no benefit in late toxicity. Three-weekly high-dose cisplatin should therefore remain the reference adjunct to radiotherapy with continuous efforts to find more efficacious and/or less toxic modalities. Unfortunately, weekly cisplatin has not convincingly met these requirements yet. Nevertheless, some clinical situation may indeed prioritize this approach.

Elderly people have often numerous comorbidities, impaired autonomy, decreased organ reserves, and a limited life expectancy. Geriatric assessment tools have been developed to help distinguish older patients who are fit and can be considered good candidates for standard treatment from those who are frail and should be directed towards palliative measures, but also from those who are in-between. Although the latter group, sometimes referred to as vulnerable, is typically excluded from registration trials, these patients may still be deemed suitable for curative therapy. Notwithstanding the lack of rigorous scientific data, weekly cisplatin is one of the regimens that can be offered to them providing a compromise solution with less acute side effects and still a possible benefit in overall survival [34]. A single dose of $40 \mathrm{mg} / \mathrm{m}^{2}$ can be pursued since the usual six to seven applications ensure an effective $\left(\geq 200 \mathrm{mg} / \mathrm{m}^{2}\right)$ and at the same time safe $\left(\leq 300 \mathrm{mg} / \mathrm{m}^{2}\right)$ cumulative dose. In addition, lowering the peak concentration of cisplatin, either by prolonging the infusion time or reducing cisplatin dose, can be recommended also in the presence of other relative contraindications as explained elsewhere [22].

More recently, the attention of healthcare professionals and researchers has been largely shifted towards immunotherapy which holds promise of being not only a more efficacious but mainly less toxic modality, offering thus new opportunities for frail patients as well [35]. In LA-SCCHN, several large trials are already ongoing and believed by many to become practice-changing, albeit only in high-income countries. In any case, the first results will not be available before 2021, and until then high-dose three-weekly cisplatin will retain its central position. But even later and in resource-limited regions, this schedule will not completely disappear from treatment protocols, and a choice between weekly and three-weekly cisplatin will maintain its significance for practicing physicians. 


\section{References}

1. Department of Veterans Affairs Laryngeal Cancer Study Group, Wolf GT, Fisher SG, Hong WK, Hillman R, Spaulding M, et al. Induction chemotherapy plus radiation compared with surgery plus radiation in patients with advanced laryngeal cancer. N Engl J Med. 1991;324:1685-90.

2. Lefebvre JL, Chevalier D, Luboinski B, Kirkpatrick A, Collette L, Sahmoud T. Larynx preservation in pyriform sinus cancer: preliminary results of a European Organization for Research and Treatment of cancer phase III trial. EORTC Head and Neck Cancer Cooperative Group. J Natl Cancer Inst. 1996;88:890-9.

3. Forastiere AA, Goepfert H, Maor M, Pajak TF, Weber R, Morrison W, et al. Concurrent chemotherapy and radiotherapy for organ preservation in advanced laryngeal cancer. $\mathrm{N}$ Engl $\mathrm{J}$ Med. 2003;349:2091-8.

4. Lefebvre JL, Rolland F, Tesselaar M, Bardet E, Leemans CR, Geoffrois L, et al. Phase 3 randomized trial on larynx preservation comparing sequential vs alternating chemotherapy and radiotherapy. J Natl Cancer Inst. 2009;101:142-52.

5. Adelstein DJ, Li Y, Adams GL, Wagner H Jr, Kish JA, Ensley JF, et al. An intergroup phase III comparison of standard radiation therapy and two schedules of concurrent chemoradiotherapy in patients with unresectable squamous cell head and neck cancer. J Clin Oncol. 2003;21:92-8.

6. Cooper JS, Pajak TF, Forastiere AA, Jacobs J, Campbell BH, Saxman SB, et al. Postoperative concurrent radiotherapy and chemotherapy for high-risk squamous-cell carcinoma of the head and neck. N Engl J Med. 2004;350:1937-44.

7. Bernier J, Domenge C, Ozsahin M, Matuszewska K, Lefèbvre JL, Greiner RH, et al. Postoperative irradiation with or without concomitant chemotherapy for locally advanced head and neck cancer. N Engl J Med. 2004;350:1945-52.

8. Ward MC, Ross RB, Koyfman SA, Lorenz R, Lamarre ED, Scharpf J, et al. Modern imageguided intensity-modulated radiotherapy for oropharynx cancer and severe late toxic effects: implications for clinical trial design. JAMA Otolaryngol Head Neck Surg. 2016;142:1164-70.

9. DE Felice F, Pranno N, Papi P, Brugnoletti O, Tombolini V, Polimeni A. Xerostomia and clinical outcomes in definitive intensity modulated radiotherapy (IMRT) versus three-dimensional conformal radiotherapy (3D-CRT) for head and neck squamous cell carcinoma: a metaanalysis. In Vivo. 2020;34:623-9.

10. Grégoire V, Lefebvre JL, Licitra L, Felip E. EHNS-ESMO-ESTRO guidelines working group. Squamous cell carcinoma of the head and neck: EHNS-ESMO-ESTRO clinical practice guidelines for diagnosis, treatment and follow-up. Ann Oncol. 2010;5(Suppl):v184-6.

11. Fountzilas G, Ciuleanu E, Dafni U, Plataniotis G, Kalogera-Fountzila A, Samantas E, et al. Concomitant radiochemotherapy vs radiotherapy alone in patients with head and neck cancer: a Hellenic cooperative oncology group phase III study. Med Oncol. 2004;21:95-107.

12. Gillison ML, Trotti AM, Harris J, Eisbruch A, Harari PM, Adelstein DJ, et al. Radiotherapy plus cetuximab or cisplatin in human papillomavirus-positive oropharyngeal cancer (NRG oncology RTOG 1016): a randomised, multicentre, non-inferiority trial. Lancet. 2019;393:40-50.

13. Mehanna H, Robinson M, Hartley A, Kong A, Foran B, Fulton-Lieuw T, et al. Radiotherapy plus cisplatin or cetuximab in low-risk human papillomavirus-positive oropharyngeal cancer (De-ESCALaTE HPV): an open-label randomised controlled phase 3 trial. Lancet. 2019;393:51-60.

14. Szturz P, Wouters K, Kiyota N, Tahara M, Prabhash K, Noronha V, et al. Weekly low-dose versus three-weekly high-dose Cisplatin for concurrent Chemoradiation in Locoregionally advanced non-nasopharyngeal head and neck cancer: a systematic review and meta-analysis of aggregate data. Oncologist. 2017;22:1056-66.

15. Szturz P, Wouters K, Kiyota N, Tahara M, Prabhash K, Noronha V, et al. Altered fractionation radiotherapy combined with concurrent low-dose or high-dose cisplatin in head and neck cancer: a systematic review of literature and meta-analysis. Oral Oncol. 2018;76:52-60. 
16. Boer H, Proost JH, Nuver J, Bunskoek S, Gietema JQ, Geubels BM, et al. Long-term exposure to circulating platinum is associated with late effects of treatment in testicular cancer survivors. Ann Oncol. 2015;26:2305-10.

17. Forastiere AA, Zhang Q, Weber RS, Maor MH, Goepfert H, Pajak TF, et al. Long-term results of RTOG 91-11: a comparison of three nonsurgical treatment strategies to preserve the larynx in patients with locally advanced larynx cancer. J Clin Oncol. 2013;31:845-52.

18. Spreafico A, Huang SH, Xu W, Granata R, Liu CS, Waldron JN, et al. Impact of cisplatin dose intensity on human papillomavirus-related and -unrelated locally advanced head and neck squamous cell carcinoma. Eur J Cancer. 2016;67:174-82.

19. Szturz P, Wouters K, Kiyota N, Tahara M, Prabhash K, Noronha V, et al. Low-dose vs. highdose Cisplatin: lessons learned from 59 Chemoradiotherapy trials in head and neck cancer. Front Oncol. 2019;9:86.

20. Otty Z, Skinner MB, Dass J, Collins M, Mooi J, Thuraisingam K, Sabesan S. Efficacy and tolerability of weekly low-dose cisplatin concurrent with radiotherapy in head and neck cancer patients. Asia Pac J Clin Oncol. 2011;7:287-92.

21. Nguyen-Tan PF, Zhang Q, Ang KK, Weber RS, Rosenthal DI, Soulieres D, et al. Randomized phase III trial to test accelerated versus standard fractionation in combination with concurrent cisplatin for head and neck carcinomas in the radiation therapy oncology group 0129 trial: long-term report of efficacy and toxicity. J Clin Oncol. 2014;32:3858-66.

22. Szturz P, Cristina V, Herrera Gómez RG, Bourhis J, Simon C, Vermorken JB. Cisplatin eligibility issues and alternative regimens in Locoregionally advanced head and neck cancer: recommendations for clinical practice. Front Oncol. 2019;9:464.

23. Strojan P, Vermorken JB, Beitler JJ, Saba NF, Haigentz M Jr, Bossi P, et al. Cumulative cisplatin dose in concurrent chemoradiotherapy for head and neck cancer: a systematic review. Head Neck. 2016;38(Suppl 1):E2151-8.

24. Quon H, Leong T, Haselow R, Leipzig B, Cooper J, Forastiere A. Phase III study of radiation therapy with or without cis-platinum in patients with unresectable squamous or undifferentiated carcinoma of the head and neck: an intergroup trial of the eastern cooperative oncology group (E2382). Int J Radiat Oncol Biol Phys. 2011;81:719-25.

25. Ghosh-Laskar S, Kalyani N, Gupta T, Budrukkar A, Murthy V, Sengar M, et al. Conventional radiotherapy versus concurrent chemoradiotherapy versus accelerated radiotherapy in locoregionally advanced carcinoma of head and neck: results of a prospective randomized trial. Head Neck. 2016;38:202-7.

26. Sharma A, Mohanti BK, Thakar A, Bahadur S, Bhasker S. Concomitant chemoradiation versus radical radiotherapy in advanced squamous cell carcinoma of oropharynx and nasopharynx using weekly cisplatin: a phase II randomized trial. Ann Oncol. 2010;21:2272-7.

27. Bachaud JM, David JM, Boussin G, Daly N. Combined postoperative radiotherapy and weekly cisplatin infusion for locally advanced squamous cell carcinoma of the head and neck: preliminary report of a randomized trial. Int J Radiat Oncol Biol Phys. 1991;20:243-6.

28. Bachaud JM, Cohen-Jonathan E, Alzieu C, David JM, Serrano E, Daly-Schveitzer N. Combined postoperative radiotherapy and weekly cisplatin infusion for locally advanced head and neck carcinoma: final report of a randomized trial. Int J Radiat Oncol Biol Phys. 1996;36:999-1004.

29. Brentani A, de Castro G Jr, Federico MH. Cost-effectiveness analysis of cisplatin-based chemoradiation to treat patients with unresectable, nonmetastatic head and neck cancer in Brazil. Head Neck. 2011;33:1199-205.

30. Jones DA, Mehanna H, Mistry P, Dalby M, Fulton-Lieuw T, Kong AH, et al. Cisplatin reduces costs and provides more quality adjusted life years (QALYs) than cetuximab in chemoradiotherapy for patients with HPV-positive oropharyngeal cancer (HPV1OPC). Ann Oncol. 2019;30(Suppl 5):v450-1.

31. Tsan DL, Lin CY, Kang CJ, Huang SF, Fan KH, Liao CT, et al. The comparison between weekly and three-weekly cisplatin delivered concurrently with radiotherapy for patients with postoperative high-risk squamous cell carcinoma of the oral cavity. Radiat Oncol. 2012;7:215. 
32. Noronha V, Joshi A, Patil VM, Agarwal J, Ghosh-Laskar S, Budrukkar A, et al. Once-a-week versus once-Every-3-weeks Cisplatin Chemoradiation for locally advanced head and neck cancer: a phase III randomized noninferiority trial. J Clin Oncol. 2018;36:1064-72.

33. Kunieda F, Kiyota N, Tahara M, Kodaira T, Hayashi R, Ishikura S, et al. Randomized phase II/III trial of post-operative chemoradiotherapy comparing 3-weekly cisplatin with weekly cisplatin in high-risk patients with squamous cell carcinoma of head and neck: Japan clinical oncology group study (JCOG1008). Jpn J Clin Oncol. 2014;44:770-4.

34. Szturz P, Bossi P, Vermorken JB. Systemic treatment in elderly head and neck cancer patients: recommendations for clinical practice. Curr Opin Otolaryngol Head Neck Surg. 2019;27:142-50.

35. Szturz P, Vermorken JB. Overcoming frailty in recurrent and metastatic head and neck cancer. Oral Oncol. 2020;104636

Open Access This chapter is licensed under the terms of the Creative Commons Attribution 4.0 International License (http://creativecommons.org/licenses/by/4.0/), which permits use, sharing, adaptation, distribution and reproduction in any medium or format, as long as you give appropriate credit to the original author(s) and the source, provide a link to the Creative Commons license and indicate if changes were made.

The images or other third party material in this chapter are included in the chapter's Creative Commons license, unless indicated otherwise in a credit line to the material. If material is not included in the chapter's Creative Commons license and your intended use is not permitted by statutory regulation or exceeds the permitted use, you will need to obtain permission directly from the copyright holder.

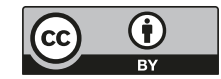

